A-rkivoc

Free to Authors and Readers
A Platinum Open Access Journal for Organic Chemistry
Paper

Arkivoc 2021, part x, 40-53

\title{
Separation, characterisation and biological evaluation of the individual isomers of the rat selective toxicant norbormide - isolated using a chemical derivatization strategy
}

\author{
Morgan Jay-Smith, ${ }^{a}$ Zifei L. Wang, ${ }^{a}$ Raida Al-Kassas, ${ }^{b}$ Elaine C. Murphy, ${ }^{c, d}$ Lee Shapiro, ${ }^{c, e}$ Charles T. Eason, ${ }^{c}$ \\ Margaret A. Brimble, ${ }^{a}$ and David Rennison*a \\ a School of Chemical Sciences, University of Auckland, Auckland, New Zealand \\ ${ }^{b}$ School of Pharmacy, University of Auckland, Auckland, New Zealand \\ ${ }^{c}$ Centre for Wildlife Management and Conservation, Lincoln University, Lincoln, New Zealand \\ ${ }^{d}$ Department of Conservation, Christchurch, New Zealand \\ ${ }^{e}$ Connovation Limited, Manukau, New Zealand \\ Email: d.rennison@auckland.ac.nz
}

Accepted Manuscript $09-29-2021 \quad$ Published on line $10-07-2021$

\section{Abstract}

Norbormide [5-( $\alpha$-hydroxy- $\alpha$-2-pyridylbenzyl)-7-( $\alpha$-2-pyridylbenzylidene)-5-norbornene-2,3-dicarboximide] (NRB, 1), an existing but infrequently used rodenticide, is known to be uniquely toxic to rats but relatively harmless to other rodents/mammals. However, as an acute vasoactive, NRB has a rapid onset of action, often leading to sub-lethal uptake/bait shyness. Recently, it was brought to our attention that baits containing two independently sourced batches of NRB (which differed noticeably in their stereochemical composition) displayed markedly different palatability/efficacy profiles in rats. Accordingly, with a view to independently evaluating the individual isomers of NRB in rats by means of a palatability and efficacy bait trial, this research describes the isolation of the individual isomers of endo-NRB $(\mathrm{Y}, \mathrm{V}, \mathrm{W}$ and $\mathrm{U})$ from the parent mixture, by means of a chemical derivatization strategy.

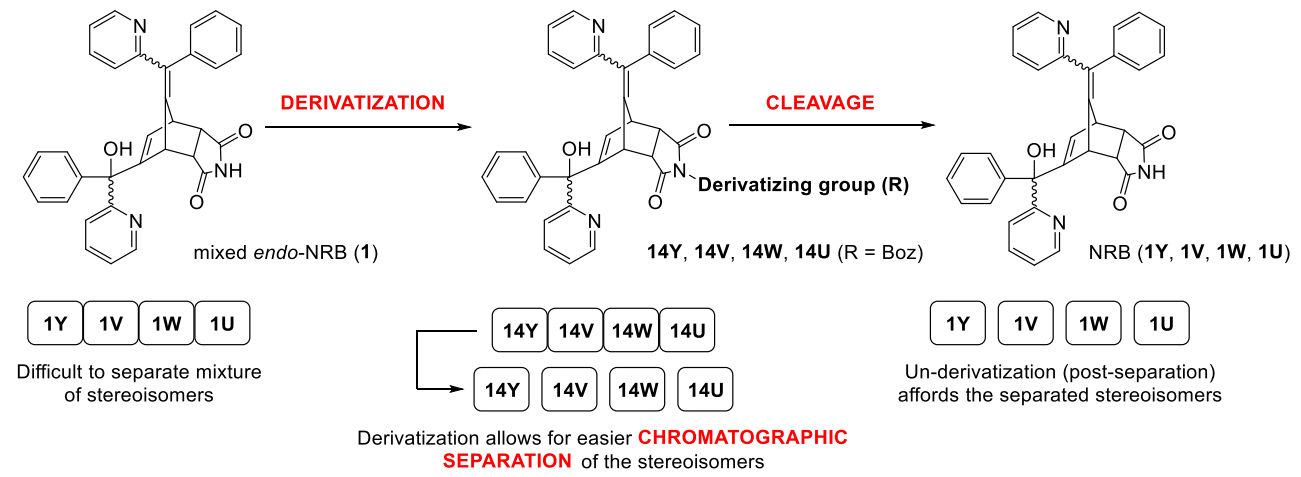

Keywords: Norbormide, stereochemistry, rodenticide, rat toxicant, particle size 


\section{Introduction}

Discovered in the 1960s, norbormide (NRB, 1) (Figure 1), a vasoactive also marketed under the trade names Shoxin ${ }^{\oplus}$ and Raticate, ${ }^{\oplus}$ was found to be uniquely toxic to rats but relatively harmless to other rodents and mammals. ${ }^{1,2}$ NRB is also known to display unique stereo- and species-specific activity both in vitro ${ }^{3,4}$ and in vivo; ${ }^{5}$ the mechanisms behind these effects have yet to be fully clarified. ${ }^{6,7}$ Disappointingly, to date, efforts to establish NRB as a viable rodenticide have been largely unsuccessful. Over time, rats have developed an evolutionary trait relating to how they sample food, particularly novel food; this survival strategy is most likely linked to their lack of an emetic centre, and thus their incapacity, as a species, to vomit. As an acute poison, NRB has a rapid onset of action in rats with toxic symptoms being registered within minutes of ingestion, and available evidence suggests that rats can develop a learnt aversion to this poison following the consumption of a sub-lethal dose during sampling, a phenomenon referred to as bait-shyness. ${ }^{8,9} \mathrm{NRB}$ is also known to be relatively unpalatable to rats. ${ }^{10-12}$ Although efforts to address this palatability problem using microencapsulation technologies have had varying degrees of success, the onset of symptoms has yet to be sufficiently delayed to significantly improve palatability, ${ }^{13,14}$ and the potential for sub-lethal dosing remains a major hurdle. More recently, a prodrug approach ${ }^{15-17}$ revealed a series of NRB derivatives which were demonstrated to be more palatable/efficacious to rats.

Recently, it was brought to our attention ${ }^{18}$ that baits (of the same formulation) containing two independently sourced batches of NRB (herein termed NRB\#A and NRB\#B) displayed markedly different palatability/efficacy profiles in rats; as demonstrated using a two-choice bait trail, where each rat was offered both poisoned and non-poisoned food (Table 1). Upon closer inspection, NRB batches \#A and \#B were both demonstrated to be of high purity, but differed noticeably in their stereochemical composition (Figure 1 and Table 2); NRB exists as a mixture of up to eight stereoisomers. ${ }^{4}$ NRB\#A was revealed to contain elevated levels of isomers $V(N R B V, \mathbf{1 V}$ ) and, to a lesser extent, $U$ (NRB $U, \mathbf{1 U})$; relative to NRB\#B. Given that consumption levels were demonstrated to be lower for bait containing NRB\#A, it was tentatively postulated that the increased presence of NRB V may, at least in part, be accountable for such an observation; NRB V is known to be the most toxic NRB isomer to rats (Table 2). ${ }^{5}$ With a view to independently evaluating the individual isomers of NRB in rats by means of a palatability and efficacy bait trial, this research describes the isolation of the individual isomers of $N R B(Y, V, W$ and $U)$ from the parent mixture by means of a chemical derivatization strategy.

Table 1. Two-choice bait-palatability and efficacy trial observations for NRB batches \#A and \#B, in SpragueDawley rats (see Figure 1 and Table 2)

\begin{tabular}{lllll}
\hline $\begin{array}{l}\text { Norbormide } \\
\text { batch }\end{array}$ & $\begin{array}{l}\text { Mean bait consumption } \\
(\mathrm{g})(\text { as a \% of body mass } \\
\pm \mathrm{SE})^{\mathrm{a}}\end{array}$ & $\begin{array}{l}\text { Mean NRB dose } \\
\text { consumed } \pm \text { SE (and } \\
\text { range) }(\mathrm{mg} / \mathrm{kg})\end{array}$ & $\begin{array}{l}\text { Mean NRB dose consumed } \\
\text { that led to death } \pm \text { SE (and } \\
\text { range) }(\mathrm{mg} / \mathrm{kg})\end{array}$ & Mortality $^{\mathrm{b}}$ \\
\hline$\# \mathrm{~A}$ & $1.35(0.39 \pm 0.05)$ & $39 \pm 5(17-70)$ & $44 \pm 7(29-61)$ & $5 / 12$ \\
$\# B$ & $1.89(0.55 \pm 0.06)$ & $55 \pm 6(35-110)$ & $56 \pm 6(35-110)$ & $11 / 12$ \\
\hline
\end{tabular}

a Rats were presented with a choice of standard lab pellets $(20 \mathrm{~g})$ and a bait formulation containing $1 \% \mathrm{w} / \mathrm{w}$ toxicant $(20 \mathrm{~g})$ for 2 days, following 3 days 'pre-feeding' with a choice of standard lab pellets and a bait formulation free of toxicant ( $n=12,6$ male rats and 6 female rats). ${ }^{b}$ Total number of rat deaths recorded/total number of rats participating in the experiment. 


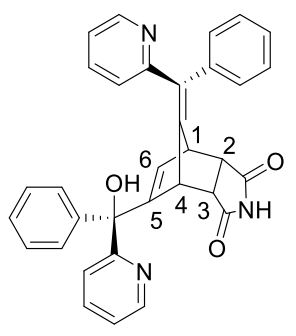

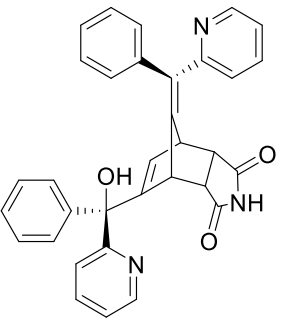

trans-endo-threo Isomer Y (1Y)

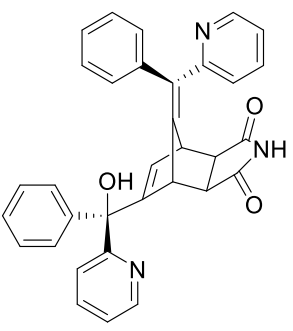

trans-exo-threo Isomer T (1T)

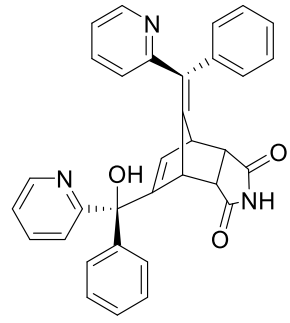

cis-endo-erythro Isomer U (1U)

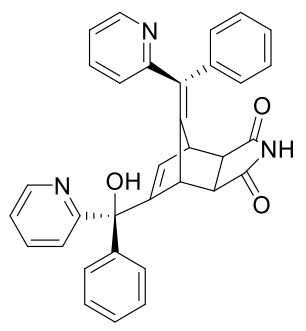

cis-exo-erythro Isomer X (1X)

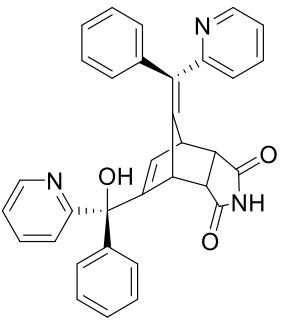

trans-endo-erythro Isomer W (1W)

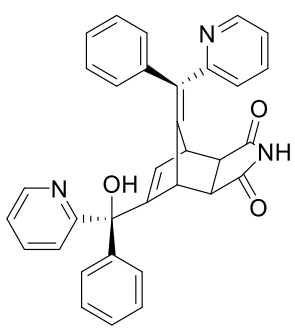

trans-exo-erythro Isomer S (1S)

Figure 1. Naming and numbering of the individual stereoisomers of NRB (1). ${ }^{4}$

Table 2. Stereoisomeric composition of NRB batches \#A and \#B, and individual NRB isomer toxicity in rats (see Figure 1$)^{5}$

\begin{tabular}{|c|c|c|c|c|c|c|c|c|}
\hline \multirow[b]{2}{*}{ Norbormide batch } & \multicolumn{8}{|c|}{ Stereoisomeric composition (\%) ${ }^{a}$} \\
\hline & $\mathrm{Y}$ & $\mathrm{V}$ & W & U & $\mathrm{R}$ & $T$ & $x$ & $S$ \\
\hline \#A & 36 & 32 & 16 & 13 & 0 & 0 & 3 & 0 \\
\hline \#B & 45 & 22 & 23 & 10 & 0 & 0 & 0 & 0 \\
\hline $\mathrm{LD}_{50}$ (rat, i.v.) mg/kg & 0.50 & 0.15 & 5.0 & 1.5 & $>10$ & $>8.5$ & $>10$ & $>8.0$ \\
\hline $\mathrm{LD}_{50}$ (rat, p.o.) mg/kg & $<5$ & 2.1 & $\mathrm{n} / \mathrm{a}$ & $\mathrm{n} / \mathrm{a}$ & $\mathrm{n} / \mathrm{a}$ & $\mathrm{n} / \mathrm{a}$ & $>100$ & $\mathrm{n} / \mathrm{a}$ \\
\hline
\end{tabular}

${ }^{\text {a }}$ As determined by achiral RP-HPLC analysis (AUC, $\lambda_{254} \mathrm{~nm}$ ), in correlation with ${ }^{1} \mathrm{H}$ NMR. ${ }^{4} \mathrm{n} / \mathrm{a}=$ Not available.

\section{Results and Discussion}

Chemical synthesis. Original research conducted by Mohrbacher and Poos over fifty years ago successfully accomplished NRB isomer separation using an exhaustive mixture of fractional recrystallization and preparative TLC methods. ${ }^{19}$ Recoveries were reported to be extremely low $(<0.01 \%$ yield), generating mere milligram quantities of the isolated NRB isomers from kilograms of mixed NRB; yet sufficient material was obtained to allow for the individual NRB isomers to be evaluated for toxicity in rats by i.v., and in some cases, p.o. (Table 2). ${ }^{5}$ Accordingly, in-house efforts to achieve a chromatographic separation of NRB using modernday techniques were undertaken, but with only limited success. Using normal phase flash chromatography methods it was not possible to attain a clean separation of all the isomers, regardless of stationary phase or eluent. 
In parallel, work continued on developing a strategy which would ultimately enable the isolation of the individual isomers of NRB, on a scale sufficient for extended in vivo biological evaluation. Previous studies working with NRB derivatives ${ }^{16,17}$ had revealed that chromatographic differentiation between the isomers could be achieved through the installation of a group on the $\mathrm{N}$-dicarboximide nitrogen. Employing a chemical derivatization strategy largely built on established literature protecting group chemistry, a selection of novel $\mathrm{N}$-dicarboximide derivatives of NRB were synthesized in an effort to induce greater differentiation between the isomers during chromatographic separation. Requirements for such a strategy fell into three main categories: 1) derivatization must be clean, and the resulting derivative be of sufficient stability to allow for its isolation; 2) a clear chromatographic separation must be attained to reveal all four major isomers present in mixed NRB (NRB Y, V, W, U); and 3) the derivatizing group must be removable under conditions to which NRB is stable. Given that NRB's tolerance to various cleavage environments was unknown, a broad range of derivatizing groups were considered.

Using Kocienski's classification of protecting groups, ${ }^{20} \mathrm{~N}$-dicarboximide derivatives 2-28 were split into 10 distinct groups based on the primary method of cleavage used for their removal (Table 3). Acid-labile (both Brønsted and Lewis acid) derivatives $2(R=T r), 11(R=E O M), 15(R=B o c)$ and $24(R=T s)$ were considered as exemplars within this particular category. Base sensitive examples included derivatives $3(R=A c), 4(R=T F A)$, $5(R=B z)$ and $14(R=B o z)$. Derivatives $6(R=B n), 7(R=N A P), 12(R=B O M)$ and $16(R=C b z)$ where primarily prepared with a view to removing the derivatizing group using hydrogen in the presence of a transition metal catalyst such as palladium(0); under mild hydrogenolysis conditions it was presumed that the tri- and tetrasubstituted olefin bonds of NRBs would be stable to such reducing environments. Conversely, following an oxidation approach, $\mathrm{PMB}$ and $\mathrm{DMB}$ groups are known to undergo single electron transfer in the presence of certain oxidants, for example ammonium cerium(IV) nitrate (CAN) or 2,3-dichloro-5,6-dicyano- $p$ benzoquinone (DDQ); which was to be probed using derivatives $8(R=P M B)$ and $\mathbf{9}(R=D M B)$. Transition metal catalysis was to be employed in the cleavage of derivatives $10(R=A l l)$ and $17(R=$ Aloc), using palladium(0) catalysts to afford $\pi$-allyl palladium complexes which could then be trapped by mild nucleophiles such as dimedone or morpholine. Two distinct families of derivatizing groups cleaved by fluoride ions (fluorideinduced fragmentation) were also explored; those where the silyl group was directly attached to the $N$ dicarboximide, for example derivatives 21 ( $R=$ TBDMS), $22(R=$ TBDPS) and $23(R=$ TIPS), and those which proceeded via a b-elimination mechanism, such as derivatives $13(R=S E M)$ and $18(R=$ Teoc). Reductive elimination (also following a 8 -elimination pathway) was to be explored using zinc-acetic acid $(\mathrm{Zn} / \mathrm{AcOH})$ in the cleavage of 2,2,2-trichloroethyl derivatives such as derivative $19(R=T r o c)$. Furthermore, alternative cleavage techniques may be employed other than the primary methods outlined above; for example derivatives 6 ( $R=$ $B n), 7(R=N A P), 16(R=C b z)$ and $24(R=T s)$ are all known to cleave under dissolving metal reduction conditions, such as sodium in liquid ammonia $\left(\mathrm{Na} / \mathrm{NH}_{3}\right)$ or lithium di-tert-butylbiphenyl (LiDBB). Mild-base catalyzed removal of the 9-fluorenylmethoxycarbonyl group, such as that found in derivative $\mathbf{2 0}(R=F m o c)$, provided a further example of a b-elimination-type approach. Finally, nosyl, and more recently tosylvinyl, groups are known to cleave under mild conditions employing thiols (e.g. $\mathrm{PhSH}$ ) in combination with bases such as DIPEA, providing examples $25(\mathrm{R}=2-\mathrm{Ns}), \mathbf{2 6}(\mathrm{R}=4-\mathrm{Ns}), \mathbf{2 7}(\mathrm{R}=\mathrm{E}-\mathrm{Tsv})$ and $\mathbf{2 8}(\mathrm{R}=\mathrm{Z}-\mathrm{Tsv})$. 
Table 3. Common methods for the removal of protecting groups used in this study

\begin{tabular}{lll}
\hline Method $^{\text {a }}$ & Reagent examples & Protecting groups \\
\hline Acid & $\mathrm{HCl}, \mathrm{TFA}, \mathrm{AlCl}_{3}$ & $\mathrm{Tr}, \mathrm{EOM}, \mathrm{Boc}, \mathrm{Ts}$ \\
Basic solvolysis & $\mathrm{K}_{2} \mathrm{CO}_{3}, \mathrm{NaOH}$ & $\mathrm{Ac}, \mathrm{TFA}, \mathrm{Bz}, \mathrm{Boz}$ \\
Hydrogenolysis & $\mathrm{Pd} / \mathrm{C}, \mathrm{Pd}(\mathrm{OH})_{2} / \mathrm{C}$ & $\mathrm{Bn}, \mathrm{NAP}, \mathrm{BOM}, \mathrm{Cbz}$ \\
Oxidation & $\mathrm{CAN}, \mathrm{DDQ}$ & $\mathrm{PMB}, \mathrm{DMB}$ \\
Transition metal catalysis & $\mathrm{Pd} /$ dimedone & All, Aloc \\
Fluoride ions & $\mathrm{TBAF}$ & TBDMS, TBDPS, TIPS, SEM, Teoc \\
Reductive elimination & $\mathrm{Zn} / \mathrm{AcOH}$ & $\mathrm{TrOc}$ \\
Dissolving metal reduction & $\mathrm{Na} / \mathrm{NH}_{3}, \mathrm{LiDBB}$ & $\mathrm{Bn}, \mathrm{NAP}, \mathrm{Cbz}, \mathrm{Ts}$ \\
6-Elimination & piperidine & $\mathrm{Fmoc}$ \\
Other & PhSH/DIPEA & $\mathrm{Ns}, \mathrm{TsV}$ \\
\hline
\end{tabular}

${ }^{\text {a }}$ Classification and abbreviations according to Kocienski. ${ }^{20}$

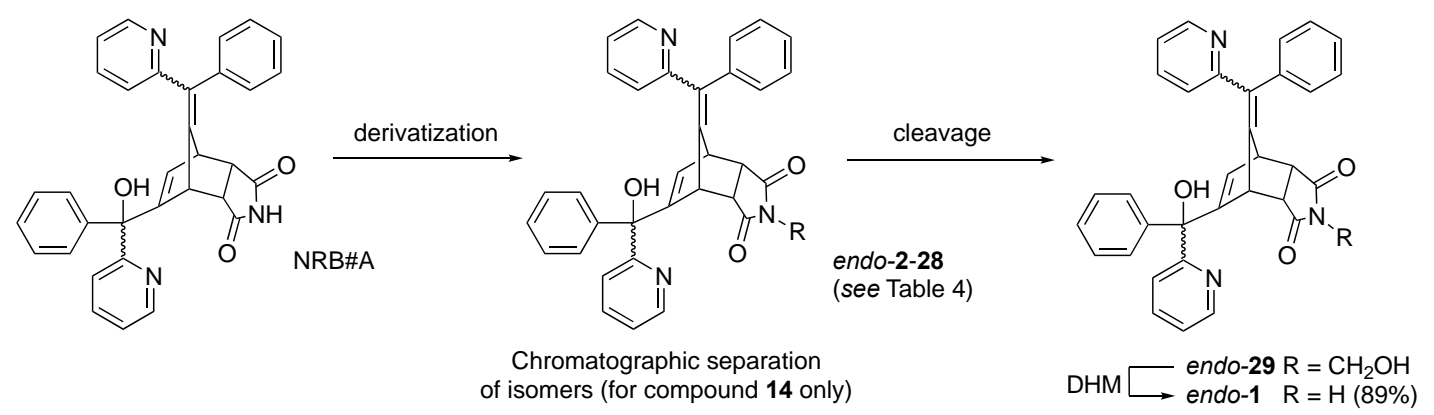

Scheme 1. General conditions. Derivatization (in conjunction with Table 4): $\operatorname{TrCl}_{1} \mathrm{Et}_{3} \mathrm{~N}, \mathrm{DCM}, \mathrm{rt}, 24 \mathrm{~h}$ (to give 2); $\mathrm{Ac}_{2} \mathrm{O}, \mathrm{Et}_{3} \mathrm{~N}, \mathrm{DMAP}, \mathrm{DCM}, \mathrm{rt}, 24 \mathrm{~h}(3)$; TFAA, $\mathrm{Et}_{3} \mathrm{~N}, \mathrm{DCM}, \mathrm{rt}, 24 \mathrm{~h} \mathrm{(4);} \mathrm{BzCl}, \mathrm{Et}_{3} \mathrm{~N}, \mathrm{DCM}, \mathrm{rt}, 24 \mathrm{~h}(5) ; \mathrm{BnCl}, \mathrm{K}_{2} \mathrm{CO}_{3}$, $\mathrm{DMF}, \mathrm{rt}, 16 \mathrm{~h}(6) ; \mathrm{NAPBr}, \mathrm{K}_{2} \mathrm{CO}_{3}, \mathrm{DMF}, \mathrm{rt}, 16 \mathrm{~h}(7) ; \mathrm{PMBCl}, \mathrm{K}_{2} \mathrm{CO}_{3}, \mathrm{DMF}, \mathrm{rt}, 16 \mathrm{~h}(8) ; \mathrm{DMBCl}, \mathrm{K}_{2} \mathrm{CO}_{3}, \mathrm{DMF}, \mathrm{rt}, 16 \mathrm{~h}$ (9); $\mathrm{AllBr}, \mathrm{K}_{2} \mathrm{CO}_{3}, \mathrm{TBAl}, \mathrm{DMF}, \mathrm{rt}, 16 \mathrm{~h}$ (10); $\mathrm{EOMCl}, \mathrm{NaH}, \mathrm{DMF}, \mathrm{rt}, 3 \mathrm{~h} \mathrm{(11);} \mathrm{BOMCl}, \mathrm{Et}{ }_{3} \mathrm{~N}, \mathrm{DCM}, \mathrm{rt}, 24 \mathrm{~h}(12)$; $\mathrm{SEMCl}, \mathrm{NaH}, \mathrm{DMF}, \mathrm{rt}, 3 \mathrm{~h}(13) ; \mathrm{BozCl}_{1} \mathrm{~K}_{2} \mathrm{CO}_{3}, \mathrm{DMF}, \mathrm{rt}, 16 \mathrm{~h}$ (14); $\mathrm{Boc}_{2} \mathrm{O}$, DMAP, DCM, rt, $16 \mathrm{~h}(15) ; \mathrm{CbzCl} \mathrm{K}_{2} \mathrm{CO}_{3}$, THF, rt, 16 h (16); AlocOSu, NaH, DMF, rt, 3 h (17); TeocONp, Et ${ }_{3} \mathrm{~N}, \mathrm{DCM}, \mathrm{rt}, 24$ h (18); $\operatorname{TrocCl}^{\mathrm{E}} \mathrm{Et}_{3} \mathrm{~N}, \mathrm{DMF}, \mathrm{rt}, 16$ h (19); FmocOSu, NaH, THF, rt, 3 h (20); TBDMSCl, NaH, DMF, rt, 16 h (21); TBDPSCl, NaH, DMF, rt, 3 h (22); TIPSCl, NaH, DMF, rt, 3 h (23); $\mathrm{TsCl}_{3} \mathrm{Et}_{3} \mathrm{~N}, \mathrm{DCM}, \mathrm{rt}, 24 \mathrm{~h}(24) ; 2-\mathrm{NsCl}_{2} \mathrm{Et}_{3} \mathrm{~N}, \mathrm{DCM}, \mathrm{rt}, 24 \mathrm{~h}(25) ; 4-\mathrm{NsCl}, \mathrm{Et}_{3} \mathrm{~N}$, $\mathrm{DCM}, \mathrm{rt}, 24 \mathrm{~h}(\mathbf{2 6})$; tosylacetylene, DMAP, $\mathrm{MeCN}, 50^{\circ} \mathrm{C}, 20 \mathrm{~h}(27)$; tosylacetylene, $\mathrm{Et}_{3} \mathrm{~N}, \mathrm{MeCN}, 0^{\circ} \mathrm{C}$ to rt, $0.5 \mathrm{~h}$ (28).

Cleavage (in conjunction with Table 5): $\mathrm{H}_{2}, \mathrm{Pd} / \mathrm{C}$, aq. $\mathrm{HCl}$ (conc.), $\mathrm{MeOH}, 3$ atm., $40{ }^{\circ} \mathrm{C}, 18 \mathrm{~h}$; $\mathrm{H}_{2}, \mathrm{Pd}(\mathrm{OH})_{2} / \mathrm{C}$, aq. $\mathrm{HCl}$ (conc.), $\mathrm{MeOH}, 3$ atm., $40{ }^{\circ} \mathrm{C}, 18 \mathrm{~h}$ (Method A); $\mathrm{H}_{2}, \mathrm{Pd}(\mathrm{OH})_{2} / \mathrm{C}, \mathrm{AcOH}, \mathrm{MeOH}, 1$ atm., rt, 18 h (Method B); $\mathrm{Na} / \mathrm{NH}_{3}, \mathrm{THF},-60^{\circ} \mathrm{C}, 2 \mathrm{~h}$; LiDBB, THF, $-78^{\circ} \mathrm{C}, 2 \mathrm{~h}$; CAN, MeCN, $\mathrm{H}_{2} \mathrm{O}, \mathrm{rt}, 18 \mathrm{~h} ; \mathrm{DDQ}, \mathrm{DCM}, \mathrm{H}_{2} \mathrm{O}, 70^{\circ} \mathrm{C}, 18 \mathrm{~h} ; 4$ $\mathrm{M} \mathrm{HCl} / 1,4$-dioxane, $\mathrm{MeOH}, 70{ }^{\circ} \mathrm{C}, 18 \mathrm{~h}$; TFA, $60{ }^{\circ} \mathrm{C}, 18 \mathrm{~h}$; $\mathrm{AlCl}_{3}, \mathrm{PhMe}, 80{ }^{\circ} \mathrm{C}, 18 \mathrm{~h}$; TBAF, THF, $60{ }^{\circ} \mathrm{C}, 4 \mathrm{~h} ; \mathrm{K}_{2} \mathrm{CO}_{3}$, $\mathrm{MeOH}, \mathrm{rt}, 18 \mathrm{~h}$. Dehydroxymethylation (DHM): i) $\mathrm{Et}_{2} \mathrm{NH}, \mathrm{DCM}, \mathrm{rt}, 1 \mathrm{~h}$, ii) $\mathrm{NaBH}(\mathrm{OAc})_{3}, \mathrm{AcOH}, \mathrm{rt}, 1 \mathrm{~h}(\mathbf{1})$.

The synthesis of derivatives 2, 5-17, 20, 23, 24, 27 and 28 (starting from NRB\#A), proceeded smoothly using standard literature methods; conversely, no product formation was observed in the preparation of compounds 18 and 25, whereas derivatives 3, 4, 19, 21, 22 and 26 were all found to be of insufficient stability and/or contained inseparable side-products (Scheme 1, Table 4). Disappointingly, on attempting 
chromatographic separation, derivatives 2, 5, 9-11, 15-17, 20, 23, 24, 27 and 28 failed to clearly reveal all 4 major isomers present within the parent NRB\#A mixture, and as a consequence these particular derivatives were abandoned. Of the derivatives which were found to separate (6-8 and 12-14) (Scheme 1, Tables 4 and 5), initial efforts to cleave benzyl derivative 6 using hydrogenolysis (both $\mathrm{Pd} / \mathrm{C}$ and $\mathrm{Pd}(\mathrm{OH})_{2} / \mathrm{C}$ ) proved unsuccessful, even at elevated temperature and pressure (all cleavage experiments were conducted on the purified stereoisomeric mixture, unless stated otherwise). Similarly, 2-naphthylmethyl derivative 7, prepared as a further example of a benzyl-type protecting group with known enhanced lability towards palladium(0)catalyzed hydrogenolysis, ${ }^{21}$ was also revealed to be stable. As an alternative method of cleavage, attempts were next made to un-derivatize compounds $\mathbf{6}$ and $\mathbf{7}$ via a dissolving metal reduction approach. Disappointingly, reactions using $\mathrm{Na} / \mathrm{NH}_{3}$ led to a complex mixture of products, as was also found to be the case using LiDBB.

Table 4. Norbormide $N$-dicarboximide derivatization and chromatographic separation (in conjunction with Scheme 1)

\begin{tabular}{lllllllll}
\hline Compound & R & Yield (\%) & Separation & Entry & Compound & R & Yield (\%) & Separation \\
\hline 2 & Tr & 18 & No & 15 & 16 & Cbz & 95 & No \\
3 & Ac & - b & - & 16 & 17 & Aloc & 36 & No \\
4 & TFA & - b & - & 17 & 18 & Teoc & - c & - \\
5 & Bz & 14 & No & 18 & 19 & Troc & - b & - \\
6 & Bn & 87 & Yes & 19 & 20 & Fmoc & 30 & No \\
7 & NAP & 96 & Yes & 20 & 21 & TBDMS & - b & - \\
8 & PMB & 57 & Yes & 21 & 22 & TBDPS & - b & - \\
9 & DMB & 72 & No & 22 & 23 & TIPS & 92 & No \\
10 & All & 77 & No & 23 & 24 & Ts & 49 & No \\
11 & EOM & 59 & No & 24 & 25 & 2-Ns & - c & - \\
12 & BOM & 78 & Yes & 25 & 26 & 4-Ns & - d & - \\
13 & SEM & 75 & Yes & 26 & 27 & E-Tsv & 80 & No \\
14 & Boz & 98 & Yes & 27 & 28 & Z-Tsv & 83 & No \\
15 & Boc & 99 & No & & & & & \\
\hline
\end{tabular}

Derivatization group $(\mathrm{R})$ abbreviations, according to Kocienski ${ }^{20}:$ Ac $=$ acetyl; All = allyl; Aloc = allyloxycarbonyl; $\mathrm{Bn}=$ benzyl; $\mathrm{Boc}=$ tert-butyloxycarbonyl; $\mathrm{BOM}=$ benzyloxymethyl; $\mathrm{Boz}=$ benzoyloxymethyl; $\mathrm{Bz}=$ benzoyl; $\mathrm{Cbz}=$ benzyloxycarbonyl; $\mathrm{DMB}=3$,4-dimethoxybenzyl; $\mathrm{EOM}=$ ethoxymethyl; Fmoc = 9-fluorenylmethoxycarbonyl; NAP = 2-naphthylmethyl; 2-Ns = 2-nosyl; 4-Ns = 4-nosyl; $\mathrm{PMB}=4$-methoxybenzyl; $\mathrm{SEM}=2$-(trimethylsilyl)ethoxymethyl; $\mathrm{TBDMS}=$ tertbutyldimethylsilyl; TBDPS = tert-butyldiphenylsilyl; Teoc = 2-(trimethylsilyl)ethoxycarbonyl; TFA = trifluoroacetyl; TIPS = triisopropylsilyl; Troc = 2,2,2-trichloroethoxycarbonyl; Tr = trityl; Ts = tosyl; Tsv

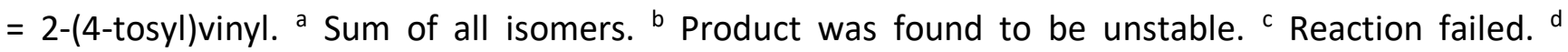
Inseparable side-products formed.

Moving our focus onto derivatizing groups designed to cleave under oxidative conditions, PMB derivative 8 was subsequently revealed to be stable in the presence of both CAN and DDQ; on the strength that both benzyl and 2-naphthylmethyl ethers are known to be more resistant to oxidative cleavage than their PMB counterparts, efforts to deprotect derivatives 6 and $\mathbf{7}$ under oxidative conditions were not pursued. ${ }^{20,22}$ On a 
related note, while PMB ethers have been reported to undergo hydrogenolysis, given that benzyl ethers are known to cleave more readily in the presence of $\mathrm{H}_{2}-\mathrm{Pd} / \mathrm{C},{ }^{20}$ and with the knowledge that derivative 6 had proven stable to such conditions, this experiment was similarly discounted. Likewise, since PMB ethers are recognized as being more stable to dissolving metal reductions than benzyl ethers, ${ }^{23}$ the deprotection of derivative $\mathbf{8}$ using such methods was not attempted. Instead, efforts to remove the PMB group of derivative $\mathbf{8}$ using Brønsted acids were investigated. Again, disappointingly, derivative $\mathbf{8}$ failed to cleave in the presence of neat trifluoroacetic acid (TFA), even at elevated temperature, while treatment with aqueous hydrochloric acid $(\mathrm{HCl})$ led only to decomposition products. Lewis acid (aluminium chloride $\left(\mathrm{AlCl}_{3}\right)$ ) methods also failed to deprotect derivative 8. Knowing that PMB ethers are generally less stable to acid than their unsubstituted benzyl counterparts, attempts to cleave derivatives 6 and $\mathbf{7}$ using either Brønsted or Lewis acids were not attempted. ${ }^{20}$

Table 5. Norbormide $N$-dicarboximide derivative cleavage method/reagent (in conjunction with Scheme 1)

\begin{tabular}{|c|c|c|c|c|}
\hline Cleavage method & Reagent & R (Compounds) & Observations & Yield $(\%)^{a}$ \\
\hline \multirow[t]{2}{*}{ Hydrogenolysis } & $\mathrm{H}_{2}, \mathrm{Pd} / \mathrm{C} ; \mathrm{Pd}(\mathrm{OH})_{2} / \mathrm{C}(\mathrm{A})$ & $\operatorname{Bn}(6), \operatorname{NAP}(7)$ & Starting material recovered & - \\
\hline & $\mathrm{H}_{2}, \mathrm{Pd}(\mathrm{OH})_{2} / \mathrm{C}(\mathrm{B})$ & BOM (12) & Gave compound 29 & 75 \\
\hline $\begin{array}{l}\text { Dissolving metal } \\
\text { reduction }\end{array}$ & $\mathrm{Na} / \mathrm{NH}_{3} ; \mathrm{LiDBB}$ & $\operatorname{Bn}(6), \operatorname{NAP}(7)$ & $\begin{array}{l}\text { Inseparable side-products } \\
\text { formed }\end{array}$ & - \\
\hline Oxidation & CAN; DDQ & PMB (8) & $\begin{array}{l}\text { Inseparable side-products } \\
\text { formed }\end{array}$ & - \\
\hline \multirow[t]{5}{*}{ Acid } & $\mathrm{HCl}$ & PMB (8) & $\begin{array}{l}\text { Inseparable side-products } \\
\text { formed }\end{array}$ & - \\
\hline & TFA; $\mathrm{AlCl}_{3}$ & PMB (8) & Starting material recovered & - \\
\hline & TFA & BOM (12) & Gave compound 29 & 76 \\
\hline & $\mathrm{HCl}$ & SEM (13) & Gave compound 29 & 82 \\
\hline & $\mathrm{HCl}$ & Boz (14) & Gave compound 29 & 91 \\
\hline Fluoride & TBAF & SEM (13) & Starting material recovered & - \\
\hline Basic solvolysis & $\mathrm{K}_{2} \mathrm{CO}_{3}$ & Boz (14) & Gave compound 29 & 73 \\
\hline
\end{tabular}

a Sum of all isomers; cleavage method and conditions initially trialled on unseparated mixture.

As a further example of a derivatizing group which permitted the required chromatographic separation of isomers, BOM derivative $\mathbf{1 2}$ was now subjected to an array of cleavage conditions. Initial approaches focused on catalytic hydrogenolysis, using $\mathrm{H}_{2}-\mathrm{Pd}(\mathrm{OH})_{2} / \mathrm{C}$ in the presence of dilute aqueous acid. Contrary to expectation, NRB was not revealed as the product of the hydrogenolysis, instead the reaction was found to terminate at $N$-hydroxymethyl NRB derivative $\mathbf{2 9}$ (in 75\% yield); it was originally anticipated that intermediate 29 would be unstable and spontaneously collapse in situ to furnish NRB. The benzyl group of BOM derivative 12 could similarly be removed under heating in TFA, again leading to $N$-hydroxymethyl NRB 29 (76\% yield). Analogous observations were noted in the cleavage of SEM derivative 13 using $\mathrm{HCl}$ (only starting materials were recovered using tetra- $n$-butylammonium fluoride (TBAF)), and in the deprotection of Boz derivative $\mathbf{1 4}$ using either aqueous acid $(\mathrm{HCl})$ or base (potassium carbonate $\left(\mathrm{K}_{2} \mathrm{CO}_{3}\right)$ ), in all instances affording $\mathrm{N}$ hydroxymethyl NRB 29 (82\%, 91\% and 73\% yield, respectively).

It has been reported that $N$-hydroxymethyl dicarboximides can be hydrolyzed under basic conditions to furnish the corresponding unsubstituted dicarboximides. ${ }^{24-29}$ Ensuing attempts to hydrolyze $N$-hydroxymethyl 
NRB 29 using ammonium hydroxide $\left(\mathrm{NH}_{4} \mathrm{OH}\right)^{25-27}$ led only to dicarboximide ring-opened side-products. In an effort to limit such unwanted hydrolysis, a selection of tertiary amine bases were screened (to be used under non-aqueous conditions). ${ }^{28,29}$ Reactions employing either $N$-methylmorpholine (NMM), 1,4diazabicyclo[2.2.2] octane (DABCO), triethylamine (TEA) or $N, N$-diisopropylethylamine (DIPEA) (in order of increasing base strength) resulted in only the partial conversion of $N$-hydroxymethyl NRB 29 to NRB (12\%, 9\%, $16 \%, 81 \%$, respectively, rt, $24 \mathrm{~h}$; according to achiral RP-HPLC of the reaction mixture). Conversely, the reaction proceeded to completion within 15 minutes in the presence of strongly basic, non-nucleophilic 1,8diazabicyclo[5.4.0]undec-7-ene (DBU) $\left(\mathrm{p} K_{\mathrm{a}} 12\right) .{ }^{30}$ Unexpectedly, upon isolation (standard aqueous work-up, $\mathrm{pH}$ 6.5) of the product, despite the reaction having apparently proceeded to $>99 \%$ completion (according to achiral RP-HPLC), an inseparable mixture of NRB and $N$-hydroxymethyl NRB 29 was observed (ca. 3:1, respectively). It is tentatively postulated that an equilibrium is in existence between $N$-hydroxymethyl NRB 29 and the corresponding reaction breakdown products, NRB and formaldehyde (thus allowing the reaction to proceed in the reverse direction during work-up) (Figure 2). Similar observations have been reported for unrelated $N$-hydroxymethyl dicarboximides. ${ }^{29}$

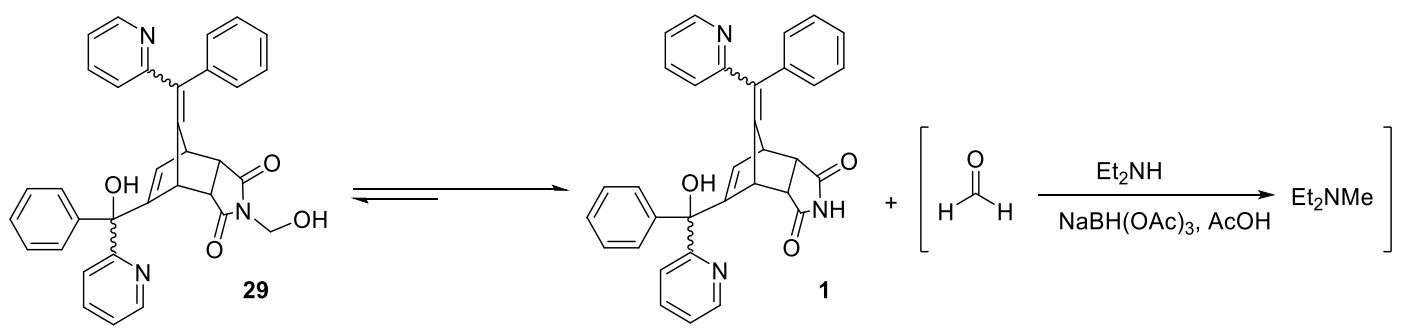

Figure 2. Postulated equilibrium between $N$-hydroxymethyl NRB derivative $\mathbf{2 9}$ and NRB (1) in the presence of formaldehyde (scavenged by means of in situ reductive amination).

On the premise that the formaldehyde generated in the reaction was indeed responsible for the $N$ hydroxymethylation of NRB during product isolation, attempts were made to sequester it from the reaction mixture using various 'scavenging' techniques. A number of reagents have been shown to selectively react with formaldehyde, including sodium bisulfite, ${ }^{31}$ tris(hydroxymethyl)aminomethane (Tris), ${ }^{32}$ semicarbazide $^{33}$ and urea. ${ }^{34}$ Alternatively, the selective reduction of aldehydes in the presence of other carbonyl-containing functional groups has been achieved using sodium triacetoxyborohydride $\left(\mathrm{NaBH}(\mathrm{OAc})_{3}\right)^{35}$ Subsequent attempts to induce the breakdown of $N$-hydroxymethyl NRB 29 in the presence of Tris failed, likely owing to its lower basicity $\left(\mathrm{p} K_{\mathrm{a}} 8.5\right) .{ }^{36}$ On repeating the reaction in the presence of both Tris (as a formaldehyde scavenger) and DBU (to promote $N$-dehydroxymethylation), again, a mixture of NRB and $N$-hydroxymethyl NRB 29 was observed post work-up. Instead, in an effort to scavenge formaldehyde by means of hydride reduction, a sequential one-pot two-step process commencing with DBU-induced $N$-dehydroxymethylation, followed by the addition of $\mathrm{NaBH}(\mathrm{OAc})_{3} / \mathrm{AcOH}$ in an attempt to consume the formaldehyde by-product, again led to a mixture of $\mathrm{NRB}$ and $\mathrm{N}$-hydroxymethyl $\mathrm{NRB}$ 29. Replacing $\mathrm{NaBH}(\mathrm{OAc})_{3}$ with the more powerful hydride source, sodium borohydride $\left(\mathrm{NaBH}_{4}\right)$, led to partial reduction of the dicarboximide ring. On a related note, $\mathrm{NaBH}(\mathrm{OAc})_{3}$ has been demonstrated to act as a mild hydride reductant in the reductive amination of both aldehydes and ketones. ${ }^{37,38}$ Correspondingly, it was proposed that substituting DBU (a tertiary amine) with a strongly basic secondary amine, for example diethylamine $\left(p K_{a} 10.5\right),{ }^{39}$ with a view to generating an iminium ion which in turn could then undergo mild selective reduction in situ (using $\left.\mathrm{NaBH}(\mathrm{OAc})_{3}\right)$, could offer an alternative way of preventing the reformation of $\mathrm{N}$-hydroxymethyl NRB 29 post cleavage (Figure 2). To our immense 
gratification, using this procedure, NRB was afforded quantitatively upon work-up (and in $89 \%$ yield after purification) (Scheme 1); note, using diethylamine in the absence of $\mathrm{NaBH}(\mathrm{OAc})_{3}$ again resulted in a mixture of NRB and $N$-hydroxymethyl NRB 29 post work-up.

Table 6. Isolated isomer recovery from NRB\#A using a chemical derivatization strategy (via Boz-protected derivative 14; following method B) (see Figure 1)

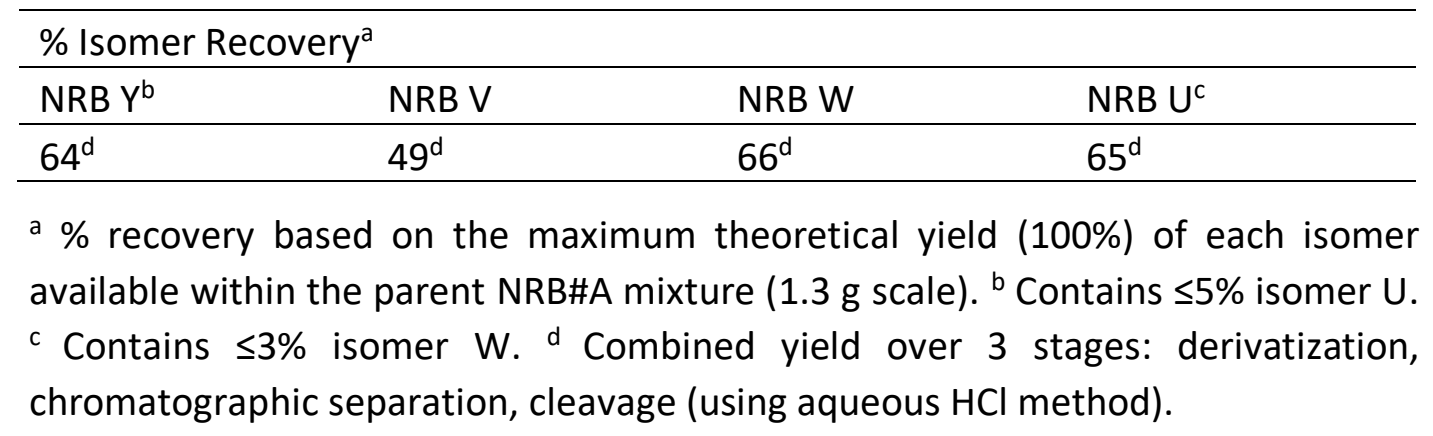

With a successful chemical derivatization/cleavage strategy now unveiled, we next set out to obtain sufficient quantities of each NRB stereoisomer to supply the intended palatability and efficacy bait trial. Basing selection on a combination of the fundamental requirements involved in the derivatization strategy (ease of derivatization, chromatographic separation and cleavage), an approach proceeding via Boz derivative 14 was nominated as the best available route (Scheme 1, Tables 4 and 5). Starting from mixed NRB, sequential derivatization and chromatographic separation afforded the isolated individual isomers of Boz derivative 14 in high recovery: 14Y (92\%, based on the maximum theoretical yield of each isomer available within the parent NRB\#A mixture), 14V (85\%), 14W (94\%) and 14U (92\%). Subsequent deprotection (HCl), via N-hydroxymethyl NRB 29 (not isolated), which in turn was $N$-dehydroxymethylated using diethylamine in combination with $\mathrm{NaBH}(\mathrm{OAC})_{3} / \mathrm{AcOH}$, successfully furnished NRB Y, V, W and U. Dependably, overall isomer recovery ranged between 49-66\%, emphatically surpassing previous literature isolation methods employing fractional recrystallization and preparative TLC techniques (<0.01\% yield) (Table 6). ${ }^{19}$

Scanning electron microscopy (SEM). SEM analysis of the isolated individual NRB isomers (NRB Y, V, W and U) revealed a high degree of similarity among the samples (being largely comprised of widely polydisperse particle sizes exhibiting similar crystalline morphology; minor surface-scale deviations were observable at 4000× magnification) (Figure 3).

Biological evaluation: bait palatability and efficacy trial in rats. Having now successfully isolated the individual endo-isomers of NRB using the aforementioned chemical derivatization strategy in sufficient quantity to undergo palatability and efficacy evaluation in rats, NRB $\mathrm{Y}, \mathrm{V}, \mathrm{W}$ and $\mathrm{U}$ were now assessed in a bait trial; for completeness, an exclusively exo-NRB mixture (NRB R/S/T/X) ${ }^{40}$ was appraised in parallel to determine what effect, if any, the non-lethal (to rats) isomers of NRB have on palatability. ${ }^{5}$ Following 1 day 'pre-baiting' with a highly palatable bait formulation free of toxicant, rats (Sprague-Dawley) were fed bait containing either NRB Y, V, W, U or R/S/T/X, at a concentration of either $0.3 \%$ or $0.1 \mathrm{w} / \mathrm{w}$ (Table 7); NRB\#B was employed as a positive control. Upon exchanging the non-toxic 'pre-feed' bait for bait containing either NRB Y $(0.63 \pm 0.16$, as a $\%$ of body mass), NRB V $(0.77 \pm 0.18)$ or NRB $\cup(0.86 \pm 0.09)$, consumption was found to be largely comparable across the different isomers; and similar to that of the NRB control bait (NRB\#B 0.90 \pm 0.20 ). Conversely, baits

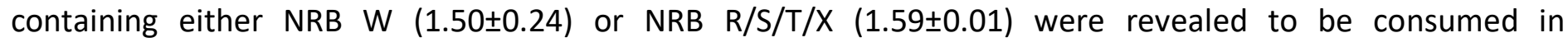


significantly greater quantities. With respect to mortality, baits containing either NRB Y (3 death recorded from a total of 4 rats) or NRB V (2/3) displayed a level of efficacy similar to that of the NRB control (NRB\#B $3 / 3)$, whereas baits containing NRB W (0/3), NRB $U(0 / 3)$ or NRB R/S/T/X (0/3) were all demonstrated to be non-lethal (in the quantities consumed). Given that NRB isomers $W, U, R, S, T$ and $X$ have all previously been demonstrated to be of relatively lower toxicity to rats (when compared directly to isomers $\mathrm{V}$ and $\mathrm{Y}$ ), ${ }^{5}$ such an observation was not entirely unexpected. Note, earlier studies working with baits containing $0.1 \% \mathrm{w} / \mathrm{w}$ toxicant (chosen on the basis of best minimizing the impact of mortality on the ensuing palatability data by working with lower \% loadings of the toxicant) failed to allow for differentiation between the toxic baits, since all baits were consumed in their entirety; no lethal endpoints were recorded (data not presented).
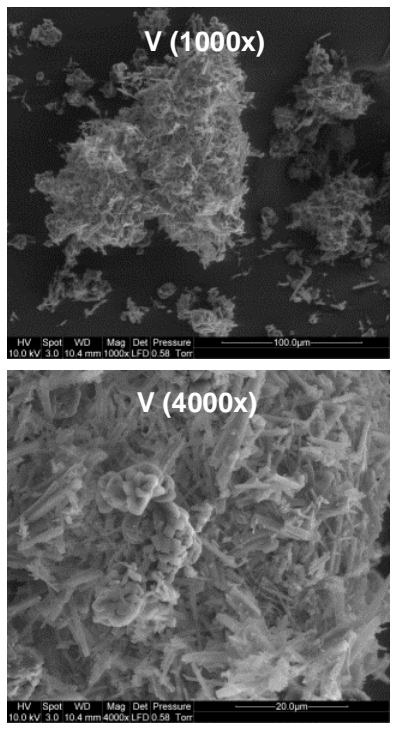
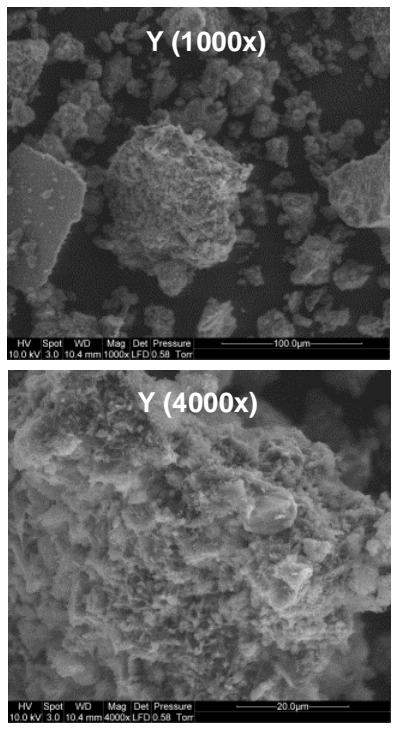
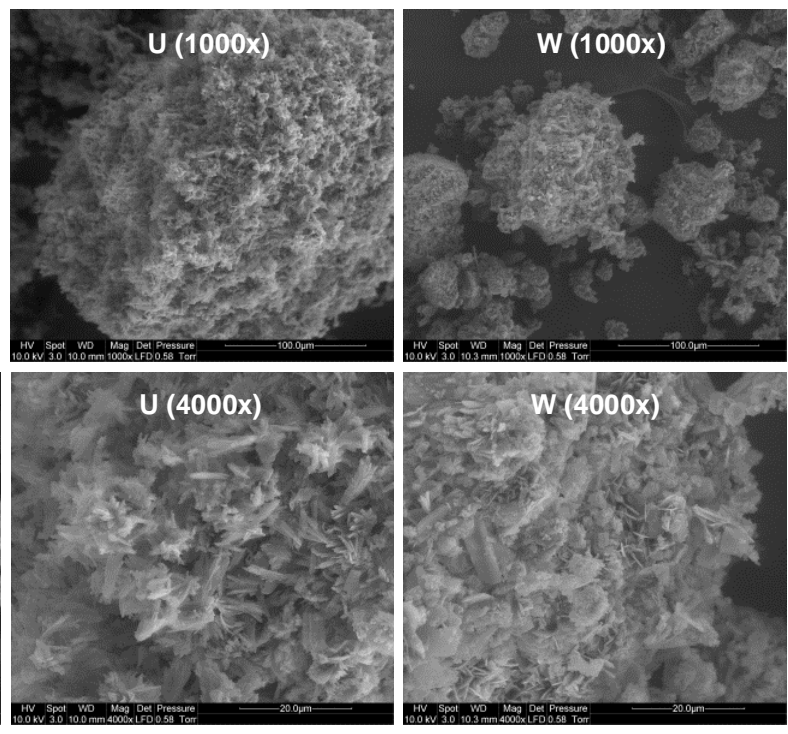

Figure 3. Scanning electron micrographs of NRB V, Y, U and W; at 1000x and 4000x magnification.

Table 7. No-choice bait-palatability and efficacy trial observations for isolated NRB isomers $Y, V, W, U$ and $\mathrm{R} / \mathrm{S} / \mathrm{T} / \mathrm{X}$, alongside NRB\#B (as a control), in Sprague-Dawley rats (see Figure 1)

\begin{tabular}{|c|c|c|c|c|}
\hline & Consumption/rat ${ }^{\mathrm{a}}$ & & & \\
\hline $\begin{array}{l}\text { Norbormide } \\
\text { Batch }\end{array}$ & $\begin{array}{l}\text { Mean bait } \\
\text { consumption }(g)^{\mathrm{b}}\end{array}$ & $\begin{array}{l}\text { Mean bait consumption as a } \\
\% \text { of body mass } \pm S E\end{array}$ & $\begin{array}{l}\text { Mean NRB dose } \\
\text { consumed } \pm \text { SE }(\mathrm{mg} / \mathrm{kg})\end{array}$ & Mortality $^{c}$ \\
\hline $\mathrm{Y}$ & 1.66 & $0.63 \pm 0.16$ & $19 \pm 6$ & $3 / 4$ \\
\hline V & 2.12 & $0.77 \pm 0.18$ & $23 \pm 5$ & $2 / 3$ \\
\hline W & 4.42 & $1.50 \pm 0.24$ & $45 \pm 7$ & $0 / 3$ \\
\hline$U$ & 2.73 & $0.86 \pm 0.09$ & $26 \pm 3$ & $0 / 3$ \\
\hline$R / S / T / X^{d}$ & 5.00 & $1.59 \pm 0.01$ & $48 \pm 1$ & $0 / 2$ \\
\hline NRB\#B & 2.72 & $0.90 \pm 0.20$ & $27 \pm 6$ & $3 / 3$ \\
\hline
\end{tabular}

a Rats were presented with the toxicant in a highly palatable bait formulation $(5 \mathrm{~g}, 0.3 \% \mathrm{w} / \mathrm{w}$ toxicant) following 1 day 'pre-feeding' with a highly palatable bait formulation free of toxicant (starting with $n=5$ for each test compound; rats which unequivocally refused to consume the 'pre-feed' bait were subsequently removed from the trial). ${ }^{\mathrm{b}}$ Over $2 \mathrm{~h}$. ${ }^{\mathrm{c}}$ Total number of rat deaths recorded/total number of rats participating in the experiment. ${ }^{d} \mathrm{R} / \mathrm{S} / \mathrm{T} / \mathrm{X}, 26: 14: 14: 46$ ratio. 


\section{Conclusions}

Each of the endo stereoisomers of $\operatorname{NRB}(\mathrm{Y}, \mathrm{V}, \mathrm{W}$ and $\mathrm{U})$ was successfully isolated using a novel chemical derivatization strategy (using methods accessible to those skilled-in-the-art, and without the need for expensive apparatus). Succinctly, through the reversible introduction of a Boz-substituent onto the $N$ dicarboximide nitrogen of NRB, chromatographic differentiation between the stereoisomers could be achieved. Subsequent cleavage of the separated NRB Boz-isomers (compound 14), using a two-step one-pot reaction procedure (via $N$-hydroxymethyl NRB 29), revealed NRB $Y, V, W$ and $U$ in good yield. Disappointingly, given the privileged pharmacological tools available as a product of this research, no clear relationship between stereochemistry and palatability/efficacy in rats was observed.

\section{Experimental Section}

General. All reagents were used as supplied, unless stated otherwise. Solvents were purified using standard methods. Analytical thin layer chromatography (TLC) was carried out on pre-coated silica gel plates (Merck/UV254) and products were visualized by UV fluorescence. Flash chromatography was performed using silica gel (Riedel-de Haën, particle size 0.032-0.063 mm). Distillation of cyclopentadiene was carried out using a Vigreux apparatus.

5-( $\alpha$-Hydroxy- $\alpha$-2-pyridylbenzyl)-7-( $\alpha$-2-pyridylbenzylidene)-5-norbornene-2,3-dicarboximide $(1 \mathrm{Y}) .{ }^{4} \quad$ To $\quad$ a solution of $14 \mathrm{Y}(159 \mathrm{mg}, 0.25 \mathrm{mmol})$ in $\mathrm{MeOH}(3 \mathrm{~mL})$ was added a solution of $\mathrm{HCl}$ in 1,4-dioxane $(3 \mathrm{~mL}, 4 \mathrm{M})$, and the mixture stirred at $70{ }^{\circ} \mathrm{C}$ for $18 \mathrm{~h}$. The solvent was then removed in vacuo and the resulting residue taken up in DCM, washed with aq. $\mathrm{NaH}_{2} \mathrm{PO}_{4} / \mathrm{Na}_{2} \mathrm{HPO}_{4}(0.5 \mathrm{M}, \mathrm{pH} 6.6)$, dried over anhydrous $\mathrm{MgSO}$, filtered and the filtrate concentrated in vacuo. The resulting residue was then taken up in a solution of $\mathrm{Et}_{2} \mathrm{NH}(25 \mu \mathrm{l}$, $0.25 \mathrm{mmol}$ ) in $\mathrm{DCM}(3 \mathrm{~mL})$, and stirred at r.t. for $1 \mathrm{~h}$. NaBH(OAc) 3 (52 mg, $0.25 \mathrm{mmol}$ ) and AcOH $(15 \mu \mathrm{l}, 0.25$ $\mathrm{mmol}$ ) were then added and the mixture stirred at r.t. for a further $1 \mathrm{~h}$. The mixture was then diluted with aq. $\mathrm{NaH}_{2} \mathrm{PO}_{4} / \mathrm{Na}_{2} \mathrm{HPO}_{4}(0.5 \mathrm{M}, \mathrm{pH}$ 6.6; to achieve a soln. $\mathrm{pH}$ of 6.6) and extracted with DCM. The combined organic extracts were then dried over anhydrous $\mathrm{MgSO}_{4}$, filtered and the filtrate concentrated in vacuo. Purification by column chromatography (petroleum ether/AcOEt, 1:1) afforded $1 Y$ ( $88 \mathrm{mg}, 70 \%$ ) as a white solid (for spectral data, see supporting information).

5-( $\alpha$-Hydroxy- $\alpha$-2-pyridylbenzyl)-7-( $\alpha$-2-pyridylbenzylidene)-5-norbornene-2,3-dicarboximide (1V). ${ }^{4} \mathrm{~A}$ similar procedure to that previously described for the preparation of $1 Y$ was followed using $14 \mathrm{~V}$ (345 $\mathrm{mg}, 0.53 \mathrm{mmol}$ ) and $\mathrm{HCl}\left(5 \mathrm{~mL}, 4 \mathrm{M}\right.$ in 1,4-dioxane) in $\mathrm{MeOH}(5 \mathrm{~mL})$, followed by Et ${ }_{2} \mathrm{NH}$ (53 $\mu \mathrm{l}, 0.53 \mathrm{mmol}$ ) in DCM (2 mL), then $\mathrm{NaBH}(\mathrm{OAc})_{3}(113 \mathrm{mg}, 0.53 \mathrm{mmol})$ and $\mathrm{AcOH}(30 \mu \mathrm{l}, 0.53 \mathrm{mmol})$. Purification by column chromatography (petroleum ether/AcOEt, 1:2) afforded $1 \mathrm{~V}$ (160 $\mathrm{mg}, 58 \%)$ as a white solid (for spectral data, see supporting information).

5-( $\alpha$-Hydroxy- $\alpha$-2-pyridylbenzyl)-7-( $\alpha$-2-pyridylbenzylidene)-5-norbornene-2,3-dicarboximide $\quad(1 \mathrm{~W}) .{ }^{4} \quad \mathrm{~A}$ similar procedure to that previously described for the preparation of $1 Y$ was followed using $14 \mathbf{W}$ (84 $\mathrm{mg}, 0.13$ $\mathrm{mmol}$ ) and $\mathrm{HCl}\left(2 \mathrm{~mL}, 4 \mathrm{M}\right.$ in 1,4-dioxane) in $\mathrm{MeOH}(2 \mathrm{~mL})$, followed by $\mathrm{Et}_{2} \mathrm{NH}(13 \mu \mathrm{l}, 0.13 \mathrm{mmol})$ in DCM (1 $\mathrm{mL}$ ), then $\mathrm{NaBH}(\mathrm{OAc})_{3}(28 \mathrm{mg}, 0.13 \mathrm{mmol})$ and $\mathrm{AcOH}(7 \mu \mathrm{l}, 0.13 \mathrm{mmol})$. Purification by column chromatography (petroleum ether/AcOEt, 1:1) afforded $\mathbf{1 W}(47 \mathrm{mg}, 70 \%)$ as a white solid (for spectral data, see supporting information). 
5-( $\alpha$-Hydroxy- $\alpha$-2-pyridylbenzyl)-7-( $\alpha$-2-pyridylbenzylidene)-5-norbornene-2,3-dicarboximide (1U). ${ }^{4}$ A similar procedure to that previously described for the preparation of $1 Y$ was followed using $14 \mathrm{U}$ (95 $\mathrm{mg}, 0.15 \mathrm{mmol}$ ) and $\mathrm{HCl}\left(2 \mathrm{~mL}, 4 \mathrm{M}\right.$ in 1,4-dioxane) in $\mathrm{MeOH}(2 \mathrm{~mL})$, followed by $\mathrm{Et}_{2} \mathrm{NH}(15 \mu \mathrm{l}, 0.15 \mathrm{mmol})$ in DCM (1 mL), then $\mathrm{NaBH}(\mathrm{OAc})_{3}(31 \mathrm{mg}, 0.15 \mathrm{mmol})$ and $\mathrm{AcOH}(9 \mu \mathrm{l}, 0.15 \mathrm{mmol})$. Purification by column chromatography (petroleum ether/AcOEt, 1:1) afforded $1 \mathrm{U}(53 \mathrm{mg}, 71 \%)$ as a white solid (for spectral data, see supporting information).

$N$-(Benzoyloxymethyl)-5-( $\alpha$-hydroxy- $\alpha$-2-pyridylbenzyl)-7-( $\alpha$-2-pyridylbenzylidene)-5-norbornene-2,3dicarboximide $(\mathbf{1 4 Y}, \mathbf{1 4 V}, \mathbf{1 4 W}, \mathbf{1 4 U}) .{ }^{15}$ To a solution of NRB\#A (1.30 g, $\left.2.54 \mathrm{mmol}\right)$ and $\mathrm{K}_{2} \mathrm{CO}_{3}(0.53 \mathrm{~g}, 3.81$ $\mathrm{mmol}$ ) in DMF $(5 \mathrm{~mL})$ was added chloromethyl benzoate ${ }^{15}(0.51 \mathrm{~g}, 3.05 \mathrm{mmol})$, and the mixture stirred at r.t. for $16 \mathrm{~h}$. The mixture was then diluted with AcOEt, washed with brine, dried over anhydrous $\mathrm{MgSO}_{4}$, filtered and the filtrate concentrated in vacuo. Purification by column chromatography (petroleum ether/AcOEt, 2:1) afforded (post separation) 14Y (540 mg, 92\%), 14V (445 mg, 85\%), 14W (246 mg, 94\%) and 14U (197 mg, $92 \%)$ (\% recovery based on maximum theoretical yield of each isomer available within the parent NRB\#A mixture), as white solids (for spectral data, see supporting information).

\section{Acknowledgements}

The authors would like to acknowledge the Ministry of Business, Innovation and Employment, New Zealand and Connovation Ltd, New Zealand for their financial support and assistance (M.J.-S.). Thanks also go to both Brian Hopkins (Landcare Research, New Zealand) and Jenn Bothwell (Lincoln University, New Zealand) for their help during the bait trials.

\section{Supplementary Material}

Experimental protocol describing the synthesis of compounds $\mathbf{1}, \mathbf{2}, \mathbf{5 - 1 7}, \mathbf{2 0}, \mathbf{2 3}, \mathbf{2 4}, \mathbf{2 7 - 2 9}$, along with the ${ }^{1} \mathrm{H}$ NMR spectra and RP-HPLC chromatograms for compounds $\mathbf{1 Y} / \mathbf{1 V} / \mathbf{1 W} / \mathbf{1 U}$ and $\mathbf{1 4 Y} / \mathbf{1 4 V} / \mathbf{1 4 W} / \mathbf{1 4 U}$, are available as Supplementary data in the online version of the text.

\section{References}

1. Roszkowski, A. P.; Poos, G. I.; Mohrbacher, R. J. Science 1964, 144, 412-413.

https://doi.org/10.1126/science.144.3617.412

2. Roszkowski, A. P. J. Pharmacol. Exp. Ther. 1965, 149, 288-299.

3. Bova, S.; Cima, L.; Golovina, V.; Luciani, S.; Cargnelli, G. Cardiovasc. Drug Rev. 2001, 19, 226-233. https://doi.org/10.1111/j.1527-3466.2001.tb00067.x

4. Brimble, M. A.; Muir, V. J.; Hopkins, B.; Bova, S. Arkivoc 2004, 1-11. https://doi.org/10.3998/ark.5550190.0005.101

5. Poos, G. I.; Mohrbacher, R. J.; Carson, E. L.; Paragamian, V.; Puma, B. M.; Rasmussen, C. R.; Roszkowski, A. P. J. Med. Chem. 1966, 9, 537-540.

https://doi.org/10.1021/jm00322a021 
6. Bova, S.; Trevisi, L.; Cima, L.; Luciani, S.; Golovina, V.; Cargnelli, G. J. Pharmacol. Exp. Ther. 2001, 296, 458463.

7. Fusi, F.; Saponara, S.; Sgaragli, G.; Cargnelli, G.; Bova, S. Br. J. Pharmacol. 2002, 137, 323-328. https://doi.org/10.1038/sj.bjp.0704877

8. Kusano, T. J. Fac. Agri. Tottori Univ. 1975, 5, 15-26.

9. Shimizu, T. Appl. Entomol. Zool. 1983, 18, 243-251. https://doi.org/10.1303/aez.18.243

10. Greaves, J. H. J. Hyg. (Lond) 1966, 64, 275-285. https://doi.org/10.1017/S0022172400040560

11. Ogushi, K.; Iwao, T. Eisei Dobutsu 1970, 21, 181-185.

12. Rennison, B. D.; Hammond, L. E.; Jones, G. L. J. Hyg. (Lond) 1968, 66, 147-158. https://doi.org/10.1017/S0022172400041012

13. Greaves, J. H.; Rowe, F. P.; Redfern, R.; Ayres, P. Nature 1968, 219, 402-403. https://doi.org/10.1038/219402a0

14. Nadian, A.; Lindblom, L. Int. J. Pharm. 2002, 242, 63-68. https://doi.org/10.1016/s0378-5173(02)00142-4

15. Rennison, D.; Laita, O.; Bova, S.; Cavalli, M.; Hopkins, B.; Linthicum, D. S.; Brimble, M. A. Bioorg. Med. Chem. 2012, 20, 3997-4011.

https://doi.org/10.1016/j.bmc.2012.05.014

16. Rennison, D.; Laita, O.; Conole, D.; Jay-Smith, M.; Knauf, J.; Bova, S.; Cavalli, M.; Hopkins, B.; Linthicum, D. S.; Brimble, M. A. Bioorg. Med. Chem. 2013, 21, 5886-5899. https://doi.org/10.1016/j.bmc.2013.06.071

17. Choi, H.; Conole, D.; Atkinson, D. J.; Laita, O.; Jay-Smith, M.; Pagano, M. A.; Ribaudo, G.; Cavalli, M.; Bova, S.; Hopkins, B.; Brimble, M. A.; Rennison, D. Chem. Biodivers. 2016, 13, 762-775. https://doi.org/10.1002/cbdv.201500241

18. Connovation Ltd, N. Z. Personal Communication.

19. Mohrbacher, R. J.; Almond, H. R.; Carson, E. L.; Rosenau, J. D.; Poos, G. I. J. Org. Chem. 1966, 31, 2141-2148 https://doi.org/10.1021/jo01345a019

20. Kocienski, P. J. Protecting Groups, 3rd Edn.; Thieme: Stuttgart, 2004.

21. Gaunt, M. J.; Yu, J.; Spencer, J. B. J. Org. Chem. 1998, 63, 4172-4173. https://doi.org/10.1021/jo980823v

22. Wright, J. A.; Yu, J.; Spencer, J. B. Tetrahedron Lett. 2001, 42, 4033-4036. https://doi.org/10.1016/S0040-4039(01)00563-9

23. Owen, R. M.; Roush, W. R. Org. Lett. 2005, 7, 3941-3944. https://doi.org/10.1021/ol0514303

24. Kodama, T.; Matsuo, C.; Ori, H.; Miyoshi, T.; Obika, S.; Miyashita, K.; Imanishi, T. Tetrahedron 2009, 65, 2116-2123. https://doi.org/10.1016/i.tet.2008.12.073

25. Marminon, C.; Pierre, A.; Pfeiffer, B.; Perez, V.; Leonce, S.; Renard, P.; Prudhomme, M. Bioorg. Med. Chem. 2003, 11, 679-687. https://doi.org/10.1016/S0968-0896(02)00532-1

26. Conchon, E.; Anizon, F.; Aboab, B.; Golsteyn, R. M.; Leonce, S.; Pfeiffer, B.; Prudhomme, M. Eur. J. Med. Chem. 2008, 43, 282-292. 
27. Messaoudi, S.; Anizon, F.; Pfeiffer, B.; Prudhomme, M. Tetrahedron 2005, 61, 7304-7316. https://doi.org/10.1016/i.tet.2005.04.043

28. Overman, L. E.; Rosen, M. D. Tetrahedron 2010, 66, 6514-6525.

https://doi.org/10.1016/j.tet.2010.05.048

29. Elati, C. R.; Gangula, S.; Naredla, A.; Ashok, S.; Bhattacharya, A.; Bandichhor, R. Synth. Commun. 2008, 38, 2950-2957.

https://doi.org/10.1080/00397910802005281

30. Blanchette, M. A.; Choy, W.; Davis, J. T.; Essenfeld, A. P.; Masamune, S.; Roush, W. R.; Sakai, T. Tetrahedron Lett. 1984, 25, 2183-2186.

https://doi.org/10.1016/S0040-4039(01)80205-7

31. Costa, N. A.; Pereira, J.; Ferra, J.; Cruz, P.; Martins, J.; Martins, J.; Martins, J.; Magalhães, F. D.; Mendes, A.; Carvalho, L. H. Wood Sci. Technol. 2013, 47, 1261-1272.

https://doi.org/10.1007/s00226-013-0573-4

32. Sutherland, B. W.; Toews, J.; Kast, J. J. Mass. 2008, 43, 699-715.

https://doi.org/10.1002/ims.1415

33. Cutts, S. M.; Rephaeli, A.; Nudelman, A.; Hmelnitsky, I.; Phillips, D. R. Cancer Res. 2001, 61, 8194-8202.

34. Adawiah, M. A. R. a.; Zaidon, A.; Izreen, F. A. N.; Bakar, E. S.; Hamami, S. M.; Paridah, M. T. J. Trop. For. 2012, 24, 348-357.

35. Gribble, G. W.; Ferguson, D. C. J. Chem. Soc., Chem. Commun. 1975, 535-536.

https://doi.org/10.1039/C39750000535

36. Godoy-Alcántar, C.; Yatsimirsky, A. K.; Lehn, J.-M. J. Phys. Org. Chem. 2005, 18, 979-985.

https://doi.org/10.1002/poc.941

37. Abdel-Magid, A. F.; Carson, K. G.; Harris, B. D.; Maryanoff, C. A.; Shah, R. D. J. Org. Chem. 1996, 61, 38493862.

https://doi.org/10.1021/j0960057x

38. Abdel-Magid, A. F.; Mehrman, S. J. Org. Process Res. Dev. 2006, 10, 971-1031.

https://doi.org/10.1021/op0601013

39. Kolthoff, I. M.; Chantooni, M. K.; Bhowmik, S. J. Am. Chem. Soc. 1968, 90, 23-28.

https://doi.org/10.1021/ja01003a005

40. Saponara, S.; Fusi, F.; Spiga, O.; Trezza, A.; Hopkins, B.; Brimble, M. A.; Rennison, D.; Bova, S. Front.

Pharmacol. 2019, 10, 598.

https://doi.org/10.3389/fphar.2019.00598 